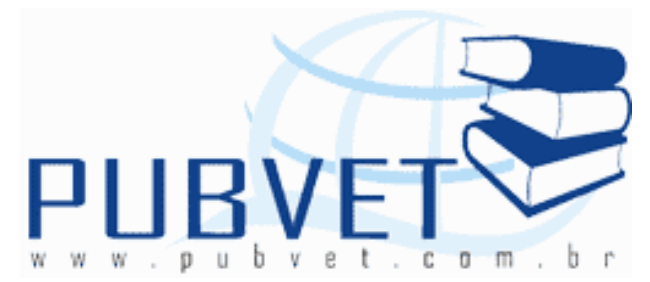

PUBVET, Publicações em Medicina Veterinária e Zootecnia.

\title{
Aspectos de qualidade do leite relacionados à ordenha manual e mecânica - revisão de literatura
}

Rafaella Belchior Brasil ${ }^{1}$; Thiago Soares Carvalho ${ }^{1}$; Cristiane Isabô Giovannini ${ }^{1}$; Liomar de Sousa Araújo루 Priscila Alonso Santos; Marco Antônio Pereira Silva ${ }^{1}$

Instituto Federal de Educação, Ciência e Tecnologia Goiano - Campus Rio Verde - GO. E-mail: rafaellabelchior@hotmail.com

\section{Resumo}

O leite bovino é um líquido complexo que contém água, glicídios (basicamente lactose), gorduras, proteínas (principalmente caseína), minerais e vitaminas em diferentes estados de dispersão, deve fazer parte da dieta por ser o alimento mais completo para o ser humano. Logo, é necessário que o mesmo apresente condições higiênicas e sanitárias adequadas e que seja livre de contaminação de qualquer espécie e isento de resíduos de antibióticos. A Contagem de Células Somáticas (CCS) é definida como o total de células presentes no leite, que podem ser do tipo epitelial ou de defesa e presente na secreção láctea pode ser um indicador da saúde da glândula mamária, de mastite subclínica, sendo aceita, também, como medida padrão para determinar a qualidade do leite. É de grande importância conhecer as características do leite produzido, pois o Brasil é um País que tem potencial para ser grande exportador de leite e abastecer o mercado mundial, por isso a relevância deste trabalho.

Palavras-chave: Contagem de Células Somáticas, leite, mastite subclínica. 


\title{
Aspects related to quality of milk to milking manual and machine - review of literature
}

\begin{abstract}
The milk is a complex fluid that contains water, carbohydrates (mainly lactose), fats, proteins (mainly casein), vitamins and minerals in different states of dispersion, should be part of the diet to be the most complete food for humans. It is there for necessary to provide the same hygienic conditions and adequate health and is free of contamination of any kind and free of antibiotic residues. The Somatic Cell Count (SCC) is defined as the total number of cells present in milk, which may be of epithelial or defense and present in milk secretion may be an indicator of the health of the mammary gland of subclinical mastitis were accepted, also, as a standard for determining the quality of milk. It is very important to know the characteristics of the milk produced, as Brazil is a country that has the potential to be big exporter of milk and supply the world market, so the relevance of this paper.
\end{abstract}

Keywords: Somatic Cell Count, milk, subclinical mastitis.

\section{INTRODUÇÃO}

A qualidade do leite é determinada por aspectos de composição e higiene, que podem ser resumidos em qualidade higiênica ou inocuidade, qualidade nutricional, qualidade sensorial e qualidade tecnológica (MONARDES, 2004).

Devido à relevância que a qualidade do leite tem para a indústria de derivados lácteos, qualquer alteração na composição natural do leite, merecem ressalva, devendo apresentar composição química (sólidos totais, gordura, proteína, lactose e minerais), microbiológica (contagem total de bactérias), sensorial (sabor, odor, aparência) e número de células somáticas (CS) que atendam aos parâmetros exigidos pela legislação (ZANELA, 2006). 
BRASIL, R.B. et al. Aspectos de qualidade do leite relacionados à ordenha manual e mecânica - revisão de literatura. PUBVET, Londrina, V. 6, N. 2, Ed. 189, Art. 1274, 2012.

Os principais fatores que afetam a composição natural do leite são a dieta, a constituição genética, a estação do ano, o estágio de lactação, o manejo da ordenha e a sanidade (DÜRR, 2004). Os parâmetros de qualidade são cada vez mais utilizados para detecção de falhas nas práticas de manejo, servindo como referência na valorização da matéria-prima. Devido à complexidade destes fatores, alguns métodos de verificação da qualidade do leite foram desenvolvidos, como o California Mastitis Test (CMT), e a Contagem de Células Somáticas (CCS).

A CCS tem sido considerada, medida padrão de qualidade, pois está relacionada com a composição, rendimento industrial e segurança alimentar do leite. Sendo para os produtores, medida de alta relevância, porque indica o estado sanitário das glândulas mamárias das vacas, podendo sinalizar para perdas significativas de produção e alterações da qualidade do leite.

O sistema de ordenha em uma propriedade leiteira é uma importante decisão a ser tomada, pois a ordenha é a última fase de uma sequência de eventos na produção de leite.

Independentemente da escolha, o sistema deve sempre permitir correta ordenha das vacas, não afetar a qualidade do leite, facilitar ao máximo o trabalho do operador, ser eficiente e estar adequadamente integrado ao sistema da propriedade. Podendo se diferenciar em dois tipos de ordenha manual e mecânica.

A Instrução Normativa 51, de 18/09/2002, do Ministério da Agricultura, Pecuária e Abastecimento (BRASIL, 2002) introduziu a regulamentação quanto aos aspectos higiênico-sanitários e de composição para a comercialização do leite, que incluíram a análise mensal do leite para determinação da composição centesimal, CCS, Contagem Bacteriana Total (CBT) e detecção de resíduos de antibióticos.

Observando que a cadeia produtiva do leite está passando por mudanças estruturais para ajustar-se as exigências de mercado e consumidores cada vez mais exigentes objetivou-se com este estudo avaliar a importância dos tipos de ordenha bem como os aspectos de qualidade do leite. 
BRASIL, R.B. et al. Aspectos de qualidade do leite relacionados à ordenha manual e mecânica

- revisão de literatura. PUBVET, Londrina, V. 6, N. 2, Ed. 189, Art. 1274, 2012.

\section{REVISÃo BIBLIOGRÁFICA}

\subsection{Produção de Leite no Brasil e no Mundo}

A origem do consumo de leite e da atividade leiteira no Brasil está intimamente ligada à exploração do gado trazido durante o período de colonização, sendo que os animais foram utilizados primeiramente como força de trabalho nos engenhos de cana de-açúcar, e posteriormente como animais de corte, sendo o consumo de leite até então, de caráter secundário com poucas vacas mantidas para esta atividade (ALVES, 2006).

Ainda de acordo com esse autor, nestes quase cinco séculos de existência, a atividade caminhou morosamente, sem grandes evoluções tecnológicas e a partir de 1950, coincidindo com o surto da industrialização do país, a pecuária leiteira entra na sua fase dita moderna, mas mesmo assim o progresso continuou muito tímido. A partir da década de 1920, algumas indústrias de beneficiamento e distribuição de leite começaram a surgir oferecendo aos consumidores, leite tratado e assim mais seguro e por volta de 1980 o setor começa a exibir um grande dinamismo.

Em todo território brasileiro a pecuária leiteira é praticada, devido às condições climáticas do país que permitem a adaptação da atividade às peculiaridades regionais, existindo diversas formas ou modelos de produção de leite, sistemas com diferentes graus de especialização, desde propriedades de subsistência, utilizando técnicas rudimentares e produção diária menor que dez litros, até produtores comparáveis aos mais competitivos do mundo, usando tecnologias avançadas e com produção diária superior a 50 mil litros (RODRIGUES, 2008).

A diversidade é a principal característica do leite no Brasil, são mais de 1,5 milhões de produtores espalhados por todas as unidades da federação, a maioria em pequenas propriedades (MARTINS, 2005).

A cadeia produtiva do leite é a mais complexa do Agronegócio Brasileiro movimentando anualmente cerca de US\$ 10 bilhões, com 3 milhões de 
BRASIL, R.B. et al. Aspectos de qualidade do leite relacionados à ordenha manual e mecânica - revisão de literatura. PUBVET, Londrina, V. 6, N. 2, Ed. 189, Art. 1274, 2012.

pessoas empregadas, das quais acima de 1 milhão são produtores e produzem aproximadamente 20 bilhões de litros de leite por ano, provenientes de um dos maiores rebanhos do mundo, com grande potencial para abastecer o mercado interno e externo (TETZNER et al., 2005).

Grandes mudanças também vêm acontecendo no perfil das agroindústrias laticinistas, na geografia da produção primária e no destino dos produtos lácteos (LEITE DPA, 2005). Porém, para atender as exigências do mercado externo, não basta os produtores aumentarem a oferta de leite, é preciso também ter qualidade e esse está sendo um fator de diferenciação entre os pecuaristas que vão permanecer no mercado e os que vão migrar para a informalidade (MINGATTO, 2005).

No sentido da melhoria da qualidade do leite, o Brasil tem empreendido grandes esforços, esses esforços iniciaram-se com o Programa Nacional de Melhoria da Qualidade do Leite (PNMQL) e culminou com a Instrução Normativa no 51, de 18 de setembro de 2002, onde através desta, o Ministério da Agricultura Pecuária e Abastecimento (MAPA) reformulou os itens utilizados para a avaliação da qualidade do leite produzido no país, que estipula valores mínimos para composição centesimal e valores máximos para CCS, CBT e estabelece prazos para que as modificações sejam implementadas nas diferentes regiões do país (TIMM et al., 2002). A Instrução Normativa no 51 no período vigente, estipula os teores mínimos de gordura, proteína bruta e sólidos desengordurados de 3,0\%, 2,9\% e 8,4\% respectivamente, CCS de 750 $\mathrm{mil} \mathrm{CS} / \mathrm{mL}$ e CBT de $750 \mathrm{mil}$ UFC/mL (BRASIL, 2002).

O Brasil segundo projeções do United States Department of Agriculture (USDA) em 2010 estava na quarta posição no ranking dos maiores países produtores de leite do mundo, com produção estimada em mais de 30 mil toneladas, ficando atrás da Índia, Rússia e Estados Unidos.

Segundo dados da USDA, os Estados Unidos foi o país que apresentou maior produção de leite em 2010, com 87.450 mil toneladas, seguido pela Índia com 50.300 mil toneladas, em terceiro a Rússia com 31.740 mil 
BRASIL, R.B. et al. Aspectos de qualidade do leite relacionados à ordenha manual e mecânica - revisão de literatura. PUBVET, Londrina, V. 6, N. 2, Ed. 189, Art. 1274, 2012.

toneladas e em quarto lugar o Brasil com produção anual de 29.480 mil toneladas (IBGE, 2010).

O Brasil é um País que tem potencial para ser grande exportador de leite e abastecer o mercado mundial, junto de países como a Argentina, Austrália, Uruguai e Nova Zelândia (GUERRA, 2004).

\subsection{Leite Como Alimento Destinado ao Consumo Humano}

Entende-se por leite, sem outra especificação, o produto oriundo da ordenha completa, e ininterrupta, em condições de higiene, de vacas sadias, bem alimentadas e descansadas, o leite de outros animais deve denominar-se segundo a espécie de que proceda (BRASIL, 2002). O leite tem sabor e aroma próprios de cada espécie, de caráter inconfundível e único, conferidos pelos seus constituintes (ARCURI, 2005).

A formação do leite demanda um enorme trabalho metabólico, requerendo a circulação de 450 litros de sangue pela glândula mamária para sintetizar um litro de leite (GONZÁLES, 2001).

Os fatores relacionados à alimentação e à nutrição são os mais importantes e os que podem ser controlados e possivelmente conhecidos em prazos relativamente curtos, embora demandem um conhecimento mais aprofundado, já que afetam não somente a fermentação no rúmen como também o metabolismo geral do animal e a secreção de leite no úbere (FREDEEN, 1996).

Para BORGES et al. (1989), o leite do ponto de vista biológico, pode ser considerado um dos alimentos mais completos, por apresentar, entre outras características, alto teor de sais minerais e proteínas, sendo que os valores nutricionais variam de acordo com diferentes espécies, raças, idade, fase de lactação e características individuais dos animais que o produzem, podendo também sofrer influências climáticas.

O leite é composto de água, suspensão coloidal de pequenas partículas de caseína, emulsão de glóbulos do leite e vitaminas lipossolúveis, as quais se 
BRASIL, R.B. et al. Aspectos de qualidade do leite relacionados à ordenha manual e mecânica - revisão de literatura. PUBVET, Londrina, V. 6, N. 2, Ed. 189, Art. 1274, 2012.

encontram em suspensão e solução de lactose, proteínas solúveis em água, sais minerais e vitaminas (BARBOSA et al., 2002). Para WALSTRA \& JENNESS (1987), o leite bovino é um líquido complexo que contém água, glicídios (basicamente lactose), gorduras, proteínas (principalmente caseína), minerais e vitaminas em diferentes estados de dispersão.

De acordo com AMÉDÉO (1997), a gordura do leite é composta pelos ácidos graxos de cadeia longa que são provenientes diretamente da alimentação ou das reservas de gordura mobilizadas do organismo, enquanto que os ácidos graxos de cadeia curta são oriundos dos produtos da fermentação ruminal.

O teor de gordura do leite depende principalmente do teor de fibra da dieta (OLIVEIRA \& FONSECA, 1999). A partir das fibras da dieta é produzido acetato que é usado na síntese da gordura do leite pela glândula mamária (TEIXEIRA, 1992).

As proteínas do leite podem ser classificadas em quatro grupos, de acordo com suas propriedades físico-químicas e estruturais: caseínas, proteínas do soro, proteínas das membranas dos glóbulos de gordura, enzimas e fatores de crescimento (LOURENÇO, 2000).

Os níveis de lactose no leite dependem principalmente da glicose que é produzida no fígado a partir do ácido propiônico produzido no rúmen, este ácido é produzido em maior proporção quando quantidades adequadas de concentrado são fornecidas aos animais (PEREIRA, 2000).

Na pecuária, a vaca assume papel de destaque na produção leiteira, gozando de universalidade indiscutível (SÁ, 1998). O leite de vaca é o mais amplamente utilizado na alimentação humana, sendo que há milhares de anos, arqueólogos encontraram evidências de ordenhas de vacas para obtenção de leite (9000 A.C) sendo os sumérios os primeiros a criar gado de corte e a utilizarem o leite na alimentação e para fabricação de manteiga (ROQUE et al., 2003).

Sendo o leite o alimento mais completo para o ser humano, deve fazer parte da dieta, em especial de crianças, idosos e convalescentes (GERMANO \& 
BRASIL, R.B. et al. Aspectos de qualidade do leite relacionados à ordenha manual e mecânica - revisão de literatura. PUBVET, Londrina, V. 6, N. 2, Ed. 189, Art. 1274, 2012.

GERMANO, 1995). Logo, é necessário que o mesmo apresente condições higiênicas e sanitárias adequadas e que seja livre de contaminação de qualquer espécie e isento de resíduos de antibióticos (COVA, 1984).

De acordo com REID (2000), as bactérias que comumente estão no leite são provenientes de fontes externas, as quais quase sempre têm como referência os equipamentos de ordenha, com destaque para os insufladores, seguidos da pele dos tetos, água e até mesmo o ar introduzido na linha de ordenha durante o processo.

Considerando o potencial de se multiplicarem, as bactérias do leite podem causar alterações químicas, tais como a degradação de gorduras, de proteínas ou de carboidratos, podendo tornar o produto impróprio para o consumo e industrialização, mesmo em animais saudáveis, a glândula mamária, a cisterna, o canal e extremidades do teto podem ser colonizados por microrganismos, porém quando o leite é resfriado, esses microrganismos cessam sua multiplicação, portanto, recomenda-se que o leite após a ordenha seja resfriado o mais rápido possível para minimizar a multiplicação pela microbiota inicial (SANTOS \& FONSECA, 2007).

A temperatura e o período de tempo de armazenagem do leite são extremamente importantes, uma vez que estes fatores estão diretamente ligados com a multiplicação dos microrganismos presentes no leite, afetando, consequentemente, a CBT (GUERREIRO et al., 2005).

O controle da qualidade do leite tem início no processo de produção da fazenda, na aquisição e manutenção de animais saudáveis através de manejo higiênico e sanitário adequados, nas etapas seguintes de industrialização, distribuição e comercialização, são inúmeros os cuidados que devem ser tomados, devendo fazer um esforço integrado para garantir a qualidade do produto final (BRITO, 1999).

Entretanto, em algumas localidades, o leite ainda é obtido sob condições higiênico-sanitárias deficientes e em consequência, apresenta elevado número de microrganismos, sob tais condições, pode constituir um risco à saúde 
BRASIL, R.B. et al. Aspectos de qualidade do leite relacionados à ordenha manual e mecânica - revisão de literatura. PUBVET, Londrina, V. 6, N. 2, Ed. 189, Art. 1274, 2012.

humana, principalmente se consumido sem tratamento térmico (SANTANA, 2008).

A qualidade do produto final está diretamente relacionada à carga microbiológica do leite ao chegar à indústria beneficiadora, sendo que a aceitação do leite fluido por parte do consumidor depende em grande parte das suas características sensoriais, tais como sabor e aroma, assim como do seu valor nutricional, atributos esses que podem ser alterados pela ação proteolítica e lipolítica de bactérias psicrotróficas, com prejuízos ao tempo de vida-de-prateleira e à qualidade do leite pasteurizado (GUERREIRO et al., 2005).

As exigências de qualidade e higiene para o leite cru e derivados lácteos são definidas com base em postulados estabelecidos para a proteção da saúde humana e preservação das propriedades nutritivas desses alimentos (BRITO, 1999).

A composição média do leite é de $87,4 \%$ de água; $3,9 \%$ de gordura; $3,2 \%$ de proteína; $4,6 \%$ de lactose e $0,9 \%$ de minerais por 100 gramas de leite (HARDING, 1995). SOUZA et al. (2003), em análise de leite bovino cru, encontraram teor lipídico de 3,4\%, GONZALEZ et al., (2001) ressaltaram que a lactose é um dos nutrientes mais estáveis da composição química do leite.

A composição química do leite é influenciada principalmente pela nutrição, sistema de manejo, raça, nível de seleção genética, sanidade da glândula mamária e fatores fisiológicos da própria lactação (LIMA, 2005). Do ponto de vista de saúde pública, ocupa lugar de destaque na nutrição humana, pois se constitui em um alimento essencial (NASCIMENTO et al., 2001).

Segundo CAMPOS (2006), o leite cru tem sido confirmado como uma das fontes mais prováveis de doenças transmitidas por alimentos na última década, principalmente no Canadá, Estados Unidos e Japão.

De acordo com MARTINS (2005), o consumidor brasileiro não conhece o produto leite, visto que uma parcela da população valoriza o leite direto da vaca (informal), sem pasteurização, por entendê-lo mais saudável. 
BRASIL, R.B. et al. Aspectos de qualidade do leite relacionados à ordenha manual e mecânica - revisão de literatura. PUBVET, Londrina, V. 6, N. 2, Ed. 189, Art. 1274, 2012.

As técnicas que dizem respeito ao marketing referem-se a estratégias e passam por inúmeras variáveis, como marca, embalagem, rótulo, agregação de valor, promoção do produto e negociação, esses são aspectos importantes para se participar de um mercado mais estruturado com novos padrões de competitividade (SILVA, 2006).

\subsection{Métodos de Obtenção do Leite e Parâmetros de Qualidade}

O momento da ordenha constitui um dos pontos críticos de maior relevância para os animais e uma séria ameaça para a qualidade do leite (GERMANO \& GERMANO, 2001).

Várias medidas devem ser tomadas durante o processo, para minimizar a transmissão de agentes mastitogênicos e diminuir o número de microrganismos que podem ser transferidos ao leite. Nesse contexto, a ordenhadeira, a mão do ordenhador, as práticas de higiene e as lesões nos tetos são fatores importantes que expõem a superfície do úbere aos microrganismos patogênicos, sendo estes transmitidos de animais infectados para não infectados durante o processo de ordenha (AMARAL et al., 2004).

Existem dois tipos de ordenha: a manual que pode ser com ou sem a presença da cria e a mecânica do tipo balde ao pé ou circuito fechado.

Independentemente do sistema, equipamentos de ordenha, tetos dos animais, tudo deve ser devidamente higienizado e desinfetado para que não cause aumento da carga microbiana do leite após a ordenha (SANTOS \& FONSECA, 2007).

A expressão pré-dipping significa imersão dos tetos em solução desinfetante antes da ordenha e, pós - dipping, significa a imersão dos tetos após a retirada dos copos coletores (FONSECA, 1998).

A CCS é definida como o total de células presentes no leite, que podem ser do tipo epitelial ou de defesa, as epiteliais são oriundas da descamação do tecido de revestimento e secretor interno da glândula mamária (MULLER, 2002). A atividade dos microrganismos no interior da glândula mamária libera 
BRASIL, R.B. et al. Aspectos de qualidade do leite relacionados à ordenha manual e mecânica - revisão de literatura. PUBVET, Londrina, V. 6, N. 2, Ed. 189, Art. 1274, 2012.

substâncias que estimulam a migração de leucócitos a fim de combater os agentes agressores aumentando, dessa maneira, a CCS (MACHADO et al., 1999). De acordo com GUERREIRO et al. (2005), a superfície dos tetos e da glândula mamária, durante o intervalo entre as ordenhas e enquanto as vacas estão deitadas, estão sujeitas à intensa contaminação da pele dos tetos e do úbere, principalmente se o ambiente estiver altamente contaminado.

Na produção e industrialização do leite, um dos fatores que mais reduz a qualidade e a quantidade do produto é a mastite, uma doença que ataca em média $15 \%$ das vacas leiteiras em todo mundo, com prevalência na ordem de $50 \%$ (GONÇALVES \& KOZICKI, 1997). A mastite consiste na inflamação da glândula mamária resultante de infecções causadas por microrganismos que penetram de forma ascendente pelo canal do teto, possibilitando a infecção da glândula mamária e aumentando a CCS (ANDRADE, 2002).

A mastite contagiosa é aquela causada por Staphylococcus aureus, Streptococcus agalactiae ou Corynebacterium bovis, cujo habitat preferencial é o interior da glândula mamária e seu controle é mais fácil e realizado através da adoção de medidas higiênicas durante o processo de ordenha (LANGONI, 2000).

Ainda de acordo com esse autor a mastite ambiental é aquela ocasionada por agentes que partilham o mesmo ecossistema da vaca, tais como: solo, piso, cama, esterco e materiais orgânicos, dentre eles destacam-se: Escherichia coli, Enterobacter sp., Klebsiella sp., Pseudomonas sp., estafilococos coagulase negativos, Streptococcus uberis e Streptococcus dysgalactiae.

Sendo assim, a desinfecção é um dos mais importantes aspectos de prevenção de enfermidades e neste contexto muitos desinfetantes foram desenvolvidos especificamente para a prevenção das doenças na indústria leiteira (BODDIE et al., 1993).

A infeç̧ão da glândula mamária dos bovinos pode ser controlada com a utilização de substâncias germicidas nos tetos antes e após a ordenha, antibioticoterapia no período de secagem, eliminação dos casos crônicos, 
BRASIL, R.B. et al. Aspectos de qualidade do leite relacionados à ordenha manual e mecânica - revisão de literatura. PUBVET, Londrina, V. 6, N. 2, Ed. 189, Art. 1274, 2012.

tratamento dos casos clínicos durante a lactação e o adequado funcionamento dos equipamentos de ordenha (PHILPOT \& NICKERSON 1992).

No entanto, problemas relacionados às infecções nas glândulas mamárias das vacas em produção resultam em leite não pasteurizado e refrigerado com alta CBT e alta CCS (HARTMANN, 2009).

De acordo com o NATIONAL MASTITIS CONCIL (1998), quanto maior a CCS, maiores serão as perdas em produção de leite.

TSENKOVA et al., (2001) relataram que a CCS presente na secreção láctea é um indicador geral da saúde da glândula mamária, amplamente utilizado como indicador de mastite subclínica, sendo aceita, também, como medida padrão para determinar a qualidade do leite.

Com o aumento na CCS, a composição do leite, a atividade enzimática, o tempo de coagulação, a produtividade e a qualidade dos derivados lácteos, são influenciados negativamente (KITCHEN, 1981). Ainda de acordo com esse autor, o leite obtido de quartos mamários de animais sadios contém de 50 a $200 \mathrm{mil} \mathrm{CS} / \mathrm{mL}$, na dependência da severidade e extensão da infecção e do tipo de microrganismo envolvido, as contagens podem variar de 200 mil a 5.000 $\mathrm{mil} \mathrm{CS} / \mathrm{mL}$ de leite.

PHILPOT \& NICKERSON, (1991) observaram uma diminuição na produção de leite variando de 5\% a 25\% com a CCS entre 140.000 a 2.280.000 mil CS/mL. Contudo, a redução na produção de leite é o fator mais importante, representando $66 \%$ a $80 \%$ das perdas totais (FETROW et al., 2000).

A contagem bacteriana do leite cru auxilia na avaliação dos procedimentos de ordenha, uma vez que a ocorrência de resultados elevados pode indicar a existência de falhas generalizadas nos procedimentos de ordenha e refrigeração do leite na propriedade (SORIANO et al., 2001).

Estudos realizados por BRITO \& VERNEQUEZ (2000), sobre contagem bacteriana da superfície de tetas de vacas submetidas a diferentes processos de higienização, relataram uma redução do número de bactérias na pele dos 
BRASIL, R.B. et al. Aspectos de qualidade do leite relacionados à ordenha manual e mecânica - revisão de literatura. PUBVET, Londrina, V. 6, N. 2, Ed. 189, Art. 1274, 2012.

tetos em mais de $90 \%$ após a mamada do bezerro, se os mesmos forem cuidadosamente higienizados.

De acordo com FONSECA (1998), a desinfecção pré-ordenha pode estimular a ejeção do leite e diminuir a contagem bacteriana no leite e nos tetos, uma vez que, a ordenha de animais com tetos sujos ou úmidos está diretamente associada a uma alta CBT. Dessa forma, PHILPOT \& NICKERSON, (2002) afirmaram que todo produtor deveria se esforçar para produzir leite com contagem padrão em placas inferior a $10 \mathrm{mil} U \mathrm{UFC} / \mathrm{mL}$. Assim, a indústria leiteira vem empregando programas de controle da mastite que visam manter a glândula mamária saudável por meio de medidas preventivas, adoção de princípios rígidos de higiene e tratamentos estratégicos de animais doentes (BRITO \& VERNEQUEZ, 2000).

Para produção de leite com qualidade e quantidade é indispensável um úbere saudável e para isto, deve-se tomar o máximo cuidado no pré e pósdipping dos tetos, mergulhar os tetos, cobrindo-os por inteiro acima da base do úbere com soluções antissépticas adequadas é uma das práticas mais importantes e indispensáveis para redução da mastite contagiosa (PEDRINI \& MARGATHO, 2003).

A temperatura de chegada do leite na indústria também e muito importante para o controle da multiplicação de microrganismos, os quais são capazes de influenciar negativamente a qualidade do leite (ROOS et al., 2002). Recomenda-se que a temperatura de armazenamento seja de $4^{\circ} \mathrm{C}$, podendo chegar no máximo até $7^{\circ} \mathrm{C}$, dentro de duas horas após o término da ordenha (DIAS, 2000).

A saúde do rebanho leiteiro, as boas práticas durante a ordenha e a conservação do leite em baixa temperatura até o momento do processamento são ações fundamentais para evitar o desenvolvimento dos microrganismos responsáveis pela sua deterioração, esses cuidados são essenciais para a fabricação de bons produtos derivados, já que a qualidade deste depende, em primeiro lugar, da boa qualidade do leite utilizado como matéria-prima (PONSANO et al., 1999). 
BRASIL, R.B. et al. Aspectos de qualidade do leite relacionados à ordenha manual e mecânica

- revisão de literatura. PUBVET, Londrina, V. 6, N. 2, Ed. 189, Art. 1274, 2012.

\section{CONSIDERAÇÕES FINAIS}

O tipo de manejo empregado na propriedade leiteira deve merecer especial atenção por parte dos produtores e responsáveis pela ordenha, pois a elevada CCS ocasiona mudanças na composição do leite, afetando a qualidade e o rendimento de derivados lácteos. Nesse sentido, a saúde do rebanho leiteiro, as boas práticas durante a ordenha e a conservação do leite em baixa temperatura, são ações fundamentais para se obter leite de qualidade.

\section{REFERÊNCIAS BIBLIOGRÁFICAS}

ALVES, D. R. Industrialização e comercialização do leite de consumo no Brasil. Associação Brasileira do Leite Longa Vida. Disponível <http://www.ablv.org.br/opniao/artigo/dsp_add_artigo.cfm?id_artigo=6> . Acesso em: 31 jul. 2006.

AMARAL, L. A. A. et al. Avaliação da eficiência da desinfecção de teteiras e dos tetos no processo de ordenha mecânica de vacas. Rev. Pesq. Vet. Bras. v.24. n. 4. p.173-177, out/dez, 2004.

AMÉDÉO, J. L'alimentation et la pathologie nutritionnelle. In: LES RENCONTRES QUALITÉ DU LAIT, I. 1997, Rennes. Annales... Rennes, 1997 p. 16 - 24.

ANDRADE, U.V.C. Fatores ambientais sobre a produção total de leite, gordura e proteína em vacas da raça holandesa na bacia leiteira de Castrolanda, Estado do Paraná. Curitiba, 64p. Dissertação (Mestrado em Ciências Veterinárias) - Setor de Ciências Agrárias, Universidade Federal do Paraná, 2002.

BARbosA, A. S.; CAVAlCANTI, F. P.; CANUTO, T. M.; ARAÚJO, A. P.; NUNES, L. S. Características Físico-Químicas e Microbiológicas do Leite Cru e Pasteurizado Consumido no Município de Queimada, PB. Departamento de Química-DQ, Universidade Estadual da Paraíba - UEPB, Campina Grande - PB, 2002.

BODDIE, R.L.; NICKERSON, S.C.; ADKINSON, R.W. Evaluation of teat gennicides of low iodine concentrations for prevention of bovine mastitis by Staphylococus aureus and Streptococcus agalactiae. Preventive Veterinary, v. 16, p.111-7, 1993.

BORGES, M.F.; BRANDÃO, S.C.C.; PINHEIRO, A.J.R.; Efeito bactericida do peróxido de hidrogênio sobre Salmonella em leite destinado a fabricação de queijos. Revista de Microbiologia, São Paulo, v. 20, 1989.

BRASIL. Instrução Normativa no 51 de 18 de setembro de 2002. Regulamentos técnicos de produção, identidade, qualidade do leite tipos A, B e C, da identidade e qualidade do leite cru refrigerado e pasteurizado e da coleta de leite cru refrigerado e de seu transporte a granel. Diário Oficial da União, Brasília, 20 set. 2002. Seção 1, n. 183, p. 13-22. 
BRITO, J.R.F.; BRITO, M.A.V.P e VERNEQUEZ, B.R.S. Contagem bacteriana da superfície de tetas de vacas submetidas a diferentes processos de higienização, incluindo a ordenha manual com participação do bezerro para estimular a descida do leite. Rev. Univ. Fed. Santa Maria, v.30, n.5, 2000.

BRITO, M.A.V.P. Influência das células somáticas na qualidade do leite. In. MARTINS, C.E.; COSTA, C.N.; BRITO, J.R.F.; YAMAGUCHI, L.C.T.; PIRES, M. de F.A. MINAS LEITE I., 1999, Juiz de Fora. Qualidade e Produtividade de Rebanhos Leiteiros. Anais... Juiz de Fora: Embrapa Gado de Leite, p. 41-46, 1999.

COVA, W.G. Prática sensitiva de deteç̧ão de penicilina no leite. Higiene Alimentar, v.3, n.2, p.100-112. 1984.

DIAS, ARISTIDES FIALHO. Influência da Temperatura na Multiplicação das Bactérias. Jornal da Producao de Leite - PDPL / RV. Ano XII, n. 136, jun. Vicosa - Minas Gerais, 2000. Disponível em: http://www.paginarural.com.br/noticia/120780/secretario-de agriculturaquer- estimularproducao-leiteira. Acesso em:29 set. 2009.

DÜRR, J.W. Programa nacional de melhoria da qualidade do leite: uma oportunidade única. In: DÜRR, J.W.; CARVALHO, M.P.; SANTOS, M.V. (Eds.) 0 compromisso com a qualidade do leite no Brasil. Passo Fundo: Editora Universidade de Passo Fundo, 2004. p.38-55.

EMBRAPA GADO DE LEITE. Parcerias institucionais. Disponível em: http://sistemasdeproducao.cnptia.embrapa.br/FontesHTML/Leite/LeiteCerrado/parcerias.html. Acesso em: 25 jun. 2011.

FETROW, J.; STEWART, S.; EICKER, S. Mastitis: an economic consideration. In: ANNUAL MEeTING NATIONAL MASTITIS COUNCIL, 39., Atlanta, 2000. Proceedings. Madison: National Mastitis Council, 2000. p.3-47.

FONSECA, L.F.L. Qualidade do leite e sua relação com equipamento de ordenha e sistema de resfriamento. I Simpósio Internacional sobre Qualidade do Leite. Curitiba, PR, Brasil, pp.54-6,1998.

FREDEEN, A.H. Considerations in the nutritional modification of milk composition. Animal Feed Science and Technology, v. 59, n. 1-3, p. 185-197, 1996.

GERMANO, P.M.L, GERMANO, M.I.S. Higiene do leite: aspectos gerais das mastites. Higiene alimentar, v.9, n.36, p. 12 - 16, 1995.

GERMANO, P.M.L.; GERMANO, M.I.S. Higiene e vigilância sanitária de alimentos. 2 ed. São Paulo: Varella, 2001. 649 p.

GONÇALVES, D.; KOZICKI, L .E. Biochemical and immunological profiles duringthe parturition period in dairy cows, with and without placental retention and mastitis. Braz. J. Vet. Res. Anim. Sci. , 34, 6, 371-382, 1997.

GONZÁLEZ, F.H.D. Composição bioquímica do leite e hormônios da lactação. In: Uso do leite para monitorar a nutrição e o metabolismo de vacas leiteiras. 1, 2001, Passo Fundo. Anais... Porto Alegre, 2001. p. 521.

GONZALEZ, H,L.; FISCHER, V, RIBEIRO, M.E.R; GOMES, J.F; STUMPF. W, SILVA, M.A . Avaliação da Qualidade do Leite na Bacia Leiteira de Pelotas, RS. Efeito dos Meses do Ano. R. Bras. Zootec., v.33, n.6, p.1531-1543, 2004. 
GOVERNO DE GOIÁS. Secretário de agricultura quer estimular produção leiteira.

GUERRA, C. Leite é alimento importante. Então por que está abandonado? Folha de Londrina. Londrina, 6 mar. 2004. Folha rural, p. 4 - 5.

GUERREIRO, P.K.; MACHADO, M.R.F.; BRAGA, G.C.; GASPARINO, E.; FRANZENER, A .S.M. Qualidade microbiológica de leite em função de técnicas profiláticas no manejo de produção. Ciênc. agrotec., Lavras, v. 29, n. 1, p. 216-222; 2005.

HARTMANN, W. Características físico-químicas, microbiológicas, de manejo e higiene na produção de leite bovino na região oeste do Paraná: ocorrência de listeria monocytogenes, Curitiba, PR, 2009, 76p. Tese de Doutorado - Curso de Pós-Graduação em Tecnologia de Alimentos, Universidade Federal do Paraná, 2009.

IBGE, Instituto Brasileiro de Geografia e Estatística, Pesquisa Pecuária Municipal, 2010.

KITCHEN, B. J. Review of the progress of dairy science: Bovine mastitis: milk compositional changes and related diagnostic tests. Journal of Dairy Research, v.48, n. p.167-188, 1981.

LANGONI, H. Tendências de modernização do setor lácteo: monitoramento da qualidade do leite pela contagem de células somáticas. Revista Educação Continuada, v.3, p.57-64, 2000.

LEITE DPA. Goiânia, v.5, n. 52, jun. 2005. Edição especial.

LOURENÇO, E.J. Tópicos de proteínas de alimentos. Jaboticabal, São Paulo: Edição Funep, 2000. capítulo 5, p.179-231.

MACHADO, P.F.; PEREIRA, A.R.; SARRIÉS, G.A. Efeitos da contagem de células somáticas na qualidade do leite e a atual situação de rebanhos brasileiros. Revista do Instituto de Laticínios Cândido Tostes, Juiz de Fora, v.54, n.309, p.10-16, 1999.

MARTINS, P. C. A importância da qualidade do leite. In: CARVALHO, M. P.; SANTOS, M. V. Estratégia e competitividade na cadeia de produção do leite. Passo Fundo: Gráfica Editora Berthier, 2005. p. $47-53$.

MINGATTO, F. Os novos caminhos para o leite brasileiro. Infozoo. v. 1, n. 1, jan./fev. 2005. Disponível em: <http://www.dracena.unesp.br/infozoo/1/n1-parte2.pdf>. Acessado em: 19 jul. 2006.

MONARDES, H. Reflexões sobre a qualidade do leite. In: DÜRR, J.W.; CARVALHO, M.P.; SANTOS, M.V. (Org.) O compromisso com a qualidade do leite no Brasil. Passo Fundo: Universidade de Passo Fundo, 2004. p. 11-37.

MÜLLER, E. E. Qualidade do leite, células somáticas e prevenção da mastite. Simpósio sobre Sustentabilidade da Pecuária Leiteira na Região Sul do Brasil, 2. Anais... Maringá, 2002. p. 206-217.

NASCIMENTO, G. G. F.; MAESTRO, V.; CAMPOS, M. S. P. Ocorrência de resíduos de antibióticos no leite comercializado em Piracicaba, SP. Revista de nutrição. Campinas-SP, v. 14, n. 2, p.119-124, 2001.

NMC - National Mastitis Council. Laboratory Handbook on Bovine Mastitis. Madison, 222p, 1998. 
OLIVEIRA, C.A.F.; FONSECA, L.F.L. Aspectos relacionados à produção, que influenciam a qualidade do leite. Higiene Alimentar, Belo Horizonte, v.13, n. 62, p.10-16, 1999.

OLIVEIRA, Ivone Dantas de et al. A prática leiteira do município de Orizona- Goiás de 1988 a 1999. Orizona - GO, 2000. Monografia. (Graduação em História). Unidade Universitária de Pires do Rio - GO, UEG.

out/dez, 2004.

PEDRINI S.C.B.; MARGATHO L.F.F. Sensibilidade de micro-organismos patogênicos isolados de casos de mastite clínica em bovinos frente a diferentes tipos de desinfetantes. Arq. Inst. Biológico, São Paulo, v.70(4), p.391-395; 2003.

PHILPOT W. N. \& NICKERSON S.C. 1992. Mastitis: Counter attack. Babson Bros. Co, Naperville, IL. 259p.

PHILPOT, W. N.; NICKERSON, S. C. Mastitis: Counter Attack. A strategy to combat mastitis. Illinois: Babson Brothers Co., 150p, 1991.

PHILPOT, W. N.; NICKERSON, S. C. Vencendo a luta contra a mastite. 1 ed. Campinas: Westfalia, 2002.

PONSANO, E. H. G.; PINTO, M. F.; LARA, J. A. F.; PIVA, F. C. Variação Sazonal e Correlação entre Propriedades do Leite Utilizadas na Avaliação de Qualidade. Revista Higiene Alimentar, n. 64, V. III, p. 35-39. Setembro de 1999.

REID, D. Como fazer a limpeza de equipamentos de ordenha. Revista Balde Branco Número 426 - Abril/2000.

RODRIGUES, M. Impacto da utilização da somatotropina bovina (bST) sobre a produção de leite e a avaliação genética de bovinos da raça Holandesa. Dissertação (Mestrado Programa de Pós-graduação em Ciências Biológicas), Faculdade de Medicina de Ribeirão Preto da Universidade de São Paulo. 59p. 2008.

ROOS, T. B.; OliVEIRA, D. S.; MORAES, C. M.; GONZALEZ, H. L.; ALEXIS, M. A.; PORTO, C. R.; TIMM, C. D. Temperatura do Leite Cru Entregue na Industria na Regiao Sudeste do Rio Grande do Sul. XXIX Congresso Brasileiro de Medicina Veterinaria, p. 126, Gramado, 2002.

SÁ, F.V. O leite e seus produtos. 6.a ed. Lisboa, Livraria Clássica, 1998. ROQUE, R.A; SCHUMACHER, S.S.P; PAVIA, P.C. Quantificação dos microorganismos pscicotróficos em leites pasteurizados tipo B e C, comercializados na cidade de São Paulo, SP. Higiene Alimentar, v.17, n. 112, p. 5968, set, 2003.

SANTANA, R.F. Qualidade microbiológica de queijo-coalho comercializado em Aracaju, SE. Arq. Bras. Med. Vet. Zootec., v.60 n.6, P- 1517, 2008.

SANTOS, M. V.; OLIVEIRA, C. A. F.; LIMA, Y. V. R.; BOTARO, B. G. Remoção de células somáticas pela microfiltração não afeta a composição e a proteólise do leite. Ciência Rural, Santa Maria, v. 36, n. 5, p. 1486 - 1493, 2006.

SANTOS; M.V.; FONSECA, L. F. L. Estratégicas para controle de mastite e melhoria da qualidade do leite. Barueri: Manole, 2007. 314p.

SILVA, P.O. R Leite: Novas Idéias Para O Velho Problema do Marketing Disponível em: http://www.iea.sp.gov.br/OUT/verTexto.php?codTexto=5654. Acesso em 2006. 
SORIANO, C.; MICHEO, C.; MENDIEIRA, V.A.; TABERA, A.; STEFANO, A.; CASASNOVAS, G.; PURRÁN, P.; CORRADETTI, A.; CARABAJAL, S. Evaluación de la calidad de leche de tanque de tambos de la Cuenca Mar y Sierras. Veterinaria Argentina, v. 18, n. 179, p. 654-667, 2001.

SOUZA, L.G; SANTOS, G.T, DAMASCENO, J.C; MATSUSHITA, M, SAKAGUTI, E.S, RIBAS, N.P;VILLALBA, R.G. Avaliação da composição e do perfil de ácidos graxos do leite de vaca cru e pasteurizado em minilaticínios. Acta Scientiarum. Animal Sciences Maringá, v. 25, no. 2, p. 331-337, 2003.

TEIXEIRA, J.C. Nutrição de ruminantes. Lavras: Edições FAEPE. 1992.

TETZNER, T. A. D.; BENEDETTI, E.; GUIMARÃES, E. C.; PERES, R.F.G. Prevalência de resíduos de antibióticos em amostras de leite cru na região do Triângulo Mineiro, MG. Revista Higiene Alimentar. São Paulo, v. 19, n. 130, p. 69 - 72, abr. 2005.

TIMM, C. D., OLIVEIRA, D. S. Nova legislação do leite no Brasil. Ciência \& Tecnologia Veterinária, v.28, n.5, p.35, 2002.

TSENKOVA, R.; ATANASSOVA, S.; KAWANO, S. Somatic cell count determination in cow's milk by near-infrared spectroscopy: A new diagnostic tool. Journal of Animal Science, v.79, p. 2550-2557, 2001.

WALSTRA, P.; JENNESS, R. Química y física lactológica. Zaragoza: Editorial Acribia, 1987, $423 \mathrm{p}$. 